\title{
Preparation and Characterization of Polymer Composite Materials Containing Magnetite
}

\author{
E. R. Sadretdinova ${ }^{1}$, Thant Zin $\operatorname{Hein}^{2}$, \\ ${ }^{1}$ Moscow Aviation Institute (National Research University) \\ Moscow, Volokolamskoe shosse, 4, 125993, \\ Russian Federation \\ ${ }^{2}$ Defense Services Technological Academy (DSTA), \\ Mandalay Lashio Highway, Pyin Oo Lwin, Mandalay Division, \\ Myanmar
}

Received: March 26, 2021. Revised: September 1, 2021. Accepted: September 11, 2021. Published: September 14, 2021.

\begin{abstract}
In this work, magnetite nanoparticles are introduced into a polyethylene melt at the stage of a viscous-flow state by standard methods of polymer processing (extrusion), which makes it possible to obtain a nanocomposite with a uniform nanofiller distribution. The phase composition and structure of the nanocomposite were confirmed by XRF, electron microscopy, and IR spectroscopy. It is shown that the preparation of $\mathrm{Fe}_{3} \mathrm{O}_{4} / \mathrm{LLDPE}$ nanocomposites is not complicated by the appearance of unidentified phases and changes in the structure of the polymer matrix.
\end{abstract}

Keywords—Composites, polymers, nanoparticles, fillers.

\section{INTRODUCTION}

$\mathrm{F}$ UNCTIONAL nanocomposites with improved physical properties allow for a variety of applications (e.g. biomedicine, micro-optics, electronics, energy conversion or storage). In most cases, the change in the expected function is correlated with the loading of the filler [1]-[15]. The resulting composite flow behavior limits primarily huge solid loads and hence property adjustments due to molding or molding constraints. Therefore, a detailed description of the properties of the composite flow prior to shaping requires data on the shear rate and temperature dependence, as well as oscillating rheological studies [16]-[21]. In the case of nanoscale fillers, specific surface area and the resulting huge polymer-filler interfacial layer dominate rheological behavior.

Magnetic nanoparticles and nanocomposites have generated significant scientific and technological interest due to their potential applications in biomedicine, information technology, magnetic resonance imaging, catalysis, telecommunications, and environmental restoration [1]-[14].

Magnetic nanocomposites usually contain magnetic nanoparticles embedded in a non-magnetic or magnetic matrix. However, magnetic nanoparticles dispersed in composites usually have a strong tendency to form agglomerates to reduce the energy associated with the high surface area to volume ratio of nanosized particles [15-24]. To avoid aggregation of magnetic nanoparticles, protection strategies have been developed to chemically stabilize unprotected magnetic nanoparticles by grafting or coating with organic species, including surfactants or polymers, or coating with an inorganic layer such as silicon dioxide or carbon. Combining these functionalized magnetic nanoparticles in a polymer or other matrices to develop magnetic nanocomposite materials has proven to be more efficient [25]-[32]. There are mainly four types of magnetic nanocomposites, i.e. inorganic core nanocomposites, self-assembled nanocomposites, silica-based magnetic nanocomposites, and organic-inorganic nanocomposites [33]-[73]. Among them, organic inorganic magnetic nanocomposites have become more interesting due to the combination of the unique properties of the organic and inorganic components in one material. Hybrid organic inorganic magnetic nanocomposite materials can be obtained in situ, ex situ, microwave exposure, coprecipitation, melt mixing, ceramic glass treatment, and plasma polymerization methods.

Modern composites have not only a wide range of physical and mechanical properties, but are also capable of directionally changing them, for example, increasing fracture toughness, regulating rigidity, strength, and other properties. These possibilities are expanded when fibers of different nature and geometry are used in composites, i.e., when creating hybrid composites. In addition, these materials are characterized by the appearance of a synergistic effect 
(coordinated joint action of several factors in one direction).

The properties of the interface or interfacial zone, first of all, the adhesive interaction between the fiber and the matrix, determine the level of properties of composites and their retention during operation. Local stresses in the composite reach their maximum values just near or directly at the interface, where material destruction usually begins. The interface must have certain properties to ensure efficient transfer of the mechanical load from the matrix to the fiber. The adhesion bond at the interface should not be destroyed under the action of thermal and shrinkage stresses arising from the difference in the temperature coefficients of linear expansion of the matrix and fiber or as a result of chemical shrinkage of the binder during its curing.

Magnetic nanoparticles can act as a new class of non-toxic and effective flame retardants. $\mathrm{Fe}_{3} \mathrm{O}_{4}$ enhanced both thermal stability and flame retardant properties of polyvinyl alcohol. Nanoparticles were synthesized by a simple precipitation reaction without using an inert atmosphere at room temperature. The nanoparticles exhibited ferromagnetic behavior at room temperature. To obtain a magnetic nanocomposite, $\mathrm{Fe}_{3} \mathrm{O}_{4}$ nanoparticles were added to polyvinyl alcohol. Dispersed nanoparticles play the role of a magnetic barrier layer, which slows down the volatilization of the product and prevents the penetration of oxygen into the sample during polymer decomposition.

The effectiveness of magnetic nanoparticles for specific biomedical applications depends on the magnetic properties of the particles, their size, and most importantly, the surface chemistry [1]-[9]. Of particular importance in the biomedical application of colloidal magnetic systems is their stability, which depends on the effective stabilization of nanoparticles, which would ensure the presence of individual nanoparticles rather than agglomerates in solutions, while not significantly affecting the magnetic properties of the material and preserving the particle surface suitable for further functionalization [10]-[18].

When creating nanocomposites, the key tasks are the development of efficient, reliable, and affordable production technologies for mass production, which make it possible to obtain materials with stable characteristics. The hand lay technique, also called wet lay, is the simplest and most widely used process for producing flat reinforced composites. The process consists of laying layers of a polymer in successive layering using an epoxy matrix. Wet-laying is a molding process that combines layers of reinforced carbon fiber with epoxy to create a high-quality laminate. Before starting the installation process, you must prepare the appropriate form. This preparation consists of cleaning the table and applying a release agent to the surface. The manual laying process can be divided into four main steps: mold preparation, epoxy coating, laying and curing. Form preparation is one of the most important steps in the installation process. This process requires dry reinforcement layers and the application of a wet epoxy matrix. They are connected together - reinforcing material, impregnated with a matrix

Nanoparticles, even with a very low volumetric content (less than $1 \%$ ), are contained in such a fragment in a very large amount, and it is impossible to model their effect at this scale level. For example, a cubic fragment of a $1 \mu \mathrm{m}$ matrix contains more than thousand nanoparticles for a given volumetric content. Therefore, in particular, the nano-modified binder is white, while the usual binder is yellow. To model such materials, it is necessary to resort to multiscale approaches and to carry out a consistent determination of effective properties at various scale levels. This task is greatly simplified if the properties of the nanomodified matrix are known from experiments. In particular, it is known that its Young's modulus is $2.5 \mathrm{GPa}$. The missing characteristic is Poisson's ratio, which can be approximately taken unchanged, or estimated on the basis of analytical calculations using the found value of the "effective" volumetric content of the filler, which was done. Further, it suffices to numerically solve the averaging problem on a representative fragment containing only nanoparticles.

At the moment, there are different methods for obtaining composite materials, but in the entire spectrum of literature, there is not enough research data on these materials. The aim of this work is to obtain a polymer nanocomposite based on linear low density polyethylene and magnetite nanoparticles on an extruder. At the moment, physical and the mechanical properties of such a composite have not been sufficiently studied, and the chemical ratio of substances in this material and the nature of the interaction of the filler of the composite material on the structure of the nanocomposite material have not been fully investigated. In addition, composites based on linear low density polyethylene are little known. The relevance of this work can also be justified by the fact that nanocomposite materials using magnetite nanoparticles are not enough to fully study their characteristics and the possibility of using them in medicine, as well as to study how the method of obtaining a nanocomposite affects its properties and structure [22]-[38].

The choice of just such a polymeric material is due to the fact that ultra-high molecular weight polyethylene is usually used for medical purposes, but since it is difficult to process under laboratory conditions, it is possible to replace such polyethylene with linear low density polyethylene. This substitution can be argued by the fact that linear polyethylene is the most optimal for work in laboratory conditions: it is much easier to obtain a nanocomposite on an extruder, and linear low-density polyethylene and ultra-high molecular weight polyethylene exhibit the same properties. In addition, linear polyethylene is biocompatible, which is further evidence of the possibility of its use in this work.

One of the defining factors that characterize the properties of polymer nanocomposites is the high proportion of the interface between the polymer matrix and the filler. The microstructure, namely the dispersed characteristics of nanoparticles, directly affect the interface and, thus, the 
macroscopic properties of nanocomposites [39]-[67]. Therefore, the study of the dispersed characteristics of nanoparticles, the possibility of controlling their sizes and homogeneous distribution in the matrix space is a key task in the technology of metal-polymer nanocomposites. The fulfillment of this task requires the use of a certain set of studies, in particular, analysis of the phase composition, microstructure, magnetic and physical-mechanical properties, and IR spectroscopy.

\section{SYNTHESIS OF NANOCOMPOSITES}

A large number of works are underway to study the use of magnetic nanoparticles in various fields, including industry and medicine. Most of the applied magnetic nanoparticles are iron oxide nanoparticles, namely magnetite $\mathrm{Fe}_{3} \mathrm{O}_{4}$. Among the methods for obtaining magnetite nanoparticles, liquid-phase methods are mainly used, which are much easier to perform and require less energy and economic costs. Among them, the most common method: the method of coprecipitation of iron salts (II, III). The advantages of the method include the rapidity of synthesis due to the rapid nucleation of nanoparticles, the ease of synthesis due to one-stage mixing of salts in an alkaline medium, a high yield of the target product due to the complete conversion of the starting components, as well as the possibility of differentiation of the morphology and composition of nanoparticles at the synthesis stage [25]-[41]. However, despite the indicated advantages, this method also has a number of disadvantages. The main problems in the rapid nucleation of nanoparticles are the problem of separation of nucleation and growth of nanoparticles, as well as the problem of the need to control after nucleation over the growth processes of monodisperse nanoparticles, which are reflected in the uniformity of nanoparticle size distribution.

Highly dispersed nanoparticles iron oxide (II, III) Highly dispersed nanoparticles iron oxide (II, III) obtained by the Elmore reaction - rapid neutralization with constant stirring of chloride salts of ferrous and ferric iron with an excess of aqueous ammonia solution in the temperature range $20-60{ }^{\circ} \mathrm{C}$.

$2 \mathrm{FeCl}_{3}+\mathrm{FeCl}_{2}+8 \mathrm{NH}_{4} \mathrm{OH}=\mathrm{Fe}_{3} \mathrm{O}_{4}+8 \mathrm{NH}_{4} \mathrm{Cl}+4 \mathrm{H}_{2} \mathrm{O}$

According to $\mathrm{X}$-ray phase analysis, the product of the chemical deposition reaction is magnetite $\mathrm{Fe}_{3} \mathrm{O}_{4}$ (Table 1).

Table 1. XRF data of magnetite nanoparticles.

\begin{tabular}{|l|l|l|l|l|}
\hline $2 \mathrm{Q} /$ deg. & $\mathrm{d} / \AA$ & $\mathrm{I}$ & $\mathrm{I}$, rel. (\%) & $(\mathrm{hkl})$ \\
\hline 28.75 & 4.614 & 22 & 53 & \\
\hline 45.65 & 2.953 & 13 & 31 & 220 \\
\hline 53.80 & 2.532 & 42 & 100 & 311 \\
\hline 66.60 & 2.086 & 11 & 25 & 400 \\
\hline 90.95 & 1.607 & 11 & 25 & 511 \\
\hline 101.80 & 1.476 & 26 & 62 & 440 \\
\hline
\end{tabular}

Broadening of lines and a small number of intense reflections in the diffraction patterns of the samples are characteristic of nanoscale systems. The average size of magnetite nanocrystallites is $15 \mathrm{~nm}$ in accordance with the calculation of coherent scattering regions using the DebyeScherrer formula, which agrees with the data of electron microscopy.

The matrix can be a thermosetting polymer - epoxy resin, which has already found many applications: from structural composites to adhesives and surface coatings. Epoxy resins already have a number of unique qualities among polymers: no shrinkage during curing, high adhesion to various substrates, good dielectric and other valuable properties [36]-[44]. Nanocomposites using thermoplastic polymers are well known and studied to improve mechanical, electrical, thermal and insulating properties. However, nanocomposites using thermosetting polymers have not been studied as widely, especially using $\mathrm{TiO}_{2}$.

Nanoparticles are usually introduced into the polymer matrix using various methods. Dispersion processes are necessary in order to transfer nanoparticles from an agglomerated state to a uniformly dispersed state [26]-[34]. The most popular are live streaming with the use of chemical methods and the use of high shear forces in the process of mechanical dispersion of the powder. Chemical methods are capable of generating individual and non-agglomerated nanoparticles within a thermosetting or thermoplastic polymer. For mechanical dispersion, ultrasonic treatment is often used, which also improves the dispersion state of nanoparticles.

Methods for the synthesis of nanocomposite materials (or nanocomposites) are divided into two main large approaches: in situ and ex situ. The creation of nanocomposites by the in situ method makes it possible to obtain simultaneously (in one stage) both a matrix and nanoparticles, obtaining a nanocomposite at the output. The advantage of the method is that it prevents particle agglomeration while maintaining a good spatial distribution in the polymer matrix. This is due to the disjoining forces caused by the molecules of polymer matrix. The main disadvantage of the method is that all the products including side products of the synthesis of nanoparticles remain in the nanocomposite, which can deteriorate the quality and purity of the obtained material.

When using the ex situ method, each stage of nanocomposite creation is brought into a separate process: from the synthesis of nanoparticles to the preparation of a nanocomposite. This method is more energy and labor intensive compared to in situ, and requires much more time. Also, special attention should be paid to the dispersion of the nanocomponent in the matrix, since during long-term storage nanoparticles are collected into larger ones and they must be dispersed by various methods, for example, by ultrasonic treatment [1]-[8]. The ex situ synthesis method is more suitable for large scale industrial applications than the in situ method.

The ex situ method, despite some drawbacks, is used more often than the more technologically advanced in situ method. There are several reasons of it. First of all, this is due to the simplicity of the approach based on the fact that in such 
reactions the synthesis of nanoparticles is not complicated by additional reactions with the polymer matrix, the resulting nanocomposite will not contain by-products associated with the formation of nanoparticles in the polymer matrix, etc.

\section{STUDYING THE PROPERTIES OF NANOCOMPOSITES}

LLDPE was used as a polymer matrix, matrix-stabilized iron (III, II) oxide nanoparticles served as a filler. The crystalline phases of the nanocomposites were identified using X-ray phase analysis. The diffractogram shown in Fig. 1, there are diffraction peaks corresponding to interplanar the distances of the crystal lattices of PE and magnetite.

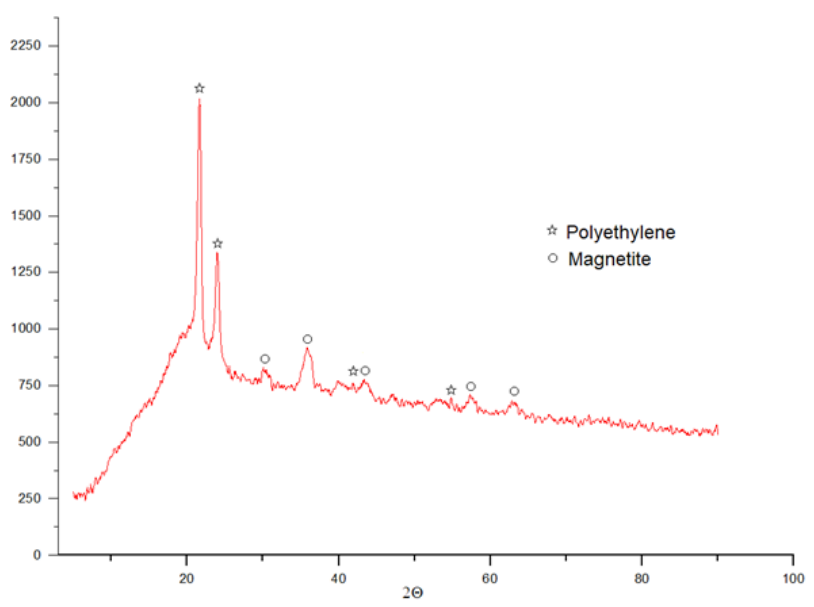

Fig. 1 Diffraction pattern of the obtained $\mathrm{Fe}_{3} \mathrm{O}_{4} /$ LLDPE nanocomposite.

Broadened peaks indicate at the presence of very small particles. No other diffraction peaks are observed on the diffraction pattern, which indicates the occurrence of the dispersion process in the polymer matrix without additional phase transformations.

Table 2. XRF data for the 10Fe3O4/ LLDPE nanocomposite.

\begin{tabular}{|l|l|l|l|l|}
\hline \multicolumn{1}{|c|}{$2 \theta / \mathrm{deg}$} & \multicolumn{1}{c|}{$\mathrm{d}$} & \multicolumn{1}{c|}{ Iimp/s } & \multicolumn{1}{c|}{ Irel (\%) } & \multicolumn{1}{c|}{ Phase } \\
\hline 21,65 & 4,105 & 1007 & 100 & LLDPE \\
\hline 23,95 & 3,715 & 477 & 43 & LLDPE \\
\hline 30,05 & 2,974 & 74 & 7 & $\mathrm{Fe}_{3} \mathrm{O}_{4}$ \\
\hline 35,85 & 2,505 & 193 & 17 & $\mathrm{Fe}_{3} \mathrm{O}_{4}$ \\
\hline 41,95 & 2,154 & 77 & 7 & LLDPE \\
\hline 43,35 & 2,087 & 94 & 9 & $\mathrm{Fe}_{3} \mathrm{O}_{4}$ \\
\hline 54,85 & 1,674 & 59 & 5 & $\mathrm{LLDPE}^{-1}$ \\
\hline 57,30 & 1,608 & 71 & 6 & $\mathrm{Fe}_{3} \mathrm{O}_{4}$ \\
\hline 62,85 & 1,479 & 74 & 7 & $\mathrm{Fe}_{3} \mathrm{O}_{4}$ \\
\hline
\end{tabular}

To determine the structure of the obtained nanocomposite, the method of IR spectroscopy was used. IR spectroscopy allows first to get evidences of the interaction between nanoparticles and polymer matrix and, second, get the information about the structure of the resulting nanocomposite. For the details of the IR characterization of the polymer nanocomposites, it is referred to the literature [48]-[50]. Fig. 2 gives the overview of IR spectra of LLDPE and the resulting nanocomposite is shown. As can be seen from the lowfrequency region of the spectrum (Fig. 3), the absorption bands of the Fe-O bond in the IR spectrum of pure magnetite are shifted in comparison with the corresponding stretching vibrations of $\mathrm{Fe}-\mathrm{O}$ in the nanocomposite, which indicates that during the mixing of the polymer and the nanofiller between the functional groups (mainly $\mathrm{OH}$ groups) on the surface of nanoparticles and the polyethylene macromolecule, a chemical interaction occurs.

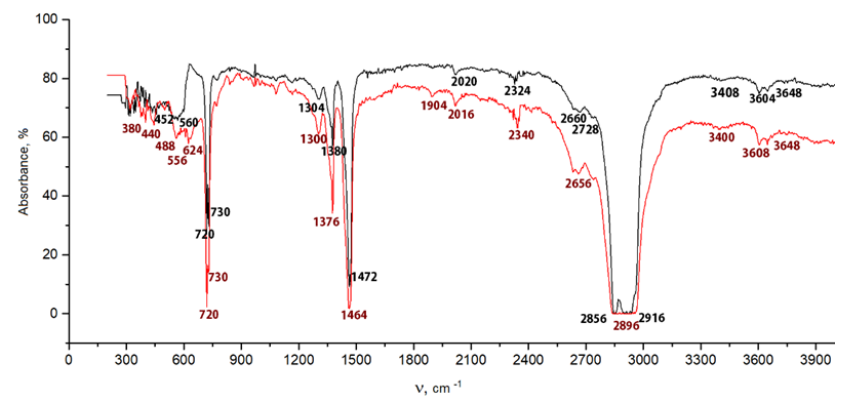

Fig. 2. ir spectrum of the obtained nanocomposite Fe3O4/LLDPE and LLDPE.

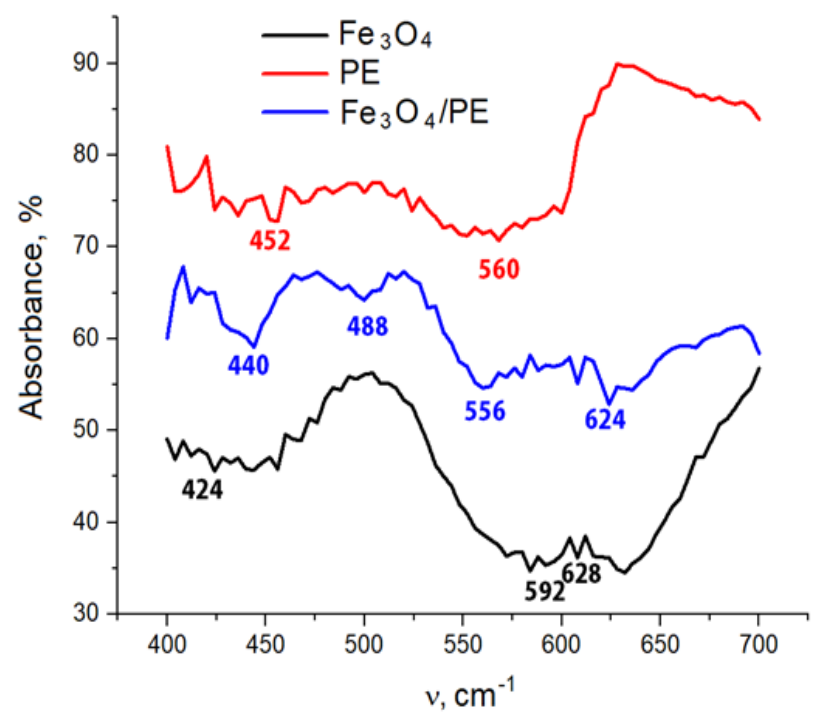

Fig. 3 ir spectrum of the nanocomposite $\mathrm{Fe}_{3} \mathrm{O}_{4} / \mathrm{LLDPE}$, LLDPE and $\mathrm{Fe}_{3} \mathrm{O}_{4}$.

It can be seen from the survey spectrum (see Fig. 2) that all characteristic LLDPE absorption bands are present in the composite. The spectra contain intense absorption bands of stretching vibrations $(\mathrm{n})>\mathrm{C}-\mathrm{H}$ at frequencies of $2856-3648$ $\mathrm{cm}^{-1}$ and 2896-3648 $\mathrm{cm}^{-1}$, respectively, and a series of bands corresponding to bending vibrations $\mathrm{dCH}_{2}: 1472,1464,1376$, 730 and $720 \mathrm{~cm}^{-1}$. Although the introduction of nanoparticles does not have a significant effect on the LLDPE structure, nevertheless, certain changes in the region of the amorphous and crystalline phases take place, as can be seen from Fig. 3, in particular, the ratio of the peaks changes, this is noticeable at $720 / 730 \mathrm{~cm}^{-1}$ and $1464 / 1472 \mathrm{~cm}^{-1}$, doublets, which indicates some amorphization of the LLDPE structure. 


\section{CONCLUSION}

As a result of this study, it was shown that the introduction of magnetite nanoparticles into the LLDPE melt at the stage of the viscous-flow state by standard methods of polymer processing (by extrusion) makes it possible to obtain a nanocomposite with a uniform distribution of the nanofiller. The phase composition and structure of the nanocomposite were confirmed by XRF, electron microscopy, and IR spectroscopy. The preparation of $\mathrm{Fe}_{3} \mathrm{O}_{4} /$ LLDPE nanocomposites is not complicated by the appearance of unidentified phases and changes in the structure of the polymer matrix. This opens new prospective for tailored fabrication of polymer nanocomposites with desired structure and properties. Further research can be aimed toward the development of nanocomposites with advanced mechanical properties.

\section{REFERENCES}

[1] L. N. Rabinskiy, S. A. Sitnikov, "Development of technologies for obtaining composite material based on silicone binder for its further use in space electric rocket engines," Periodico Tche Quimica, 15(Special Issue 1), pp. 390-395, 2018.

[2] A. A. Orekhov, Y. A. Utkin, P. F. Pronina, "Determination of deformation in mesh composite structure under the action of compressive loads," Periodico Tche Quimica, 17(35), pp. 599-608, 2020.

[3] M. Sha, Y. A. Utkin, O. V. Tushavina, P. F. Pronina, "Experimental studies of heat and mass transfer from tip models made of carbon-carbon composite material (cccm) under conditions of high-intensity thermal load," Periodico Tche Quimica, vol.17, i. 35, pp. 988-997, 2020.

[4] V. G. Dmitriev, O. V. Egorova, E. I. Starovoitov, "Particularities of mathematical modeling of deformation processes for arched and panel designs of composites with large displacements and rotation angles," INCAS Bulletin, 12(Special Issue), pp. 53-66, 2020.

[5] P. F. Pronina, O. V. Tushavina, E. I. Starovoitov, "Study of the radiation situation in Moscow by investigating elastoplastic bodies in a neutron flux taking into account thermal effects," Periodico Tche Quimica, 17(35), pp. 753-764, 2020.

[6] A. V. Babaytsev, L. N. Rabinskiy, K. T. Aung, "Investigation of the contact zone of a cylindrical shell located between two parallel rigid plates with a gap," INCAS Bulletin, 12(Special Issue), pp. 43-52, 2020.

[7] O. V. Egorova, E. I. Starovoitov, "Non-stationary diffraction problem of a plane oblique pressure wave on the shell in the form of a hyperbolic cylinder taking into account the dissipation effect," INCAS Bulletin, 12(Special Issue), pp. 67-77, 2020.

[8] O. A. Butusova, "Design and Properties of Magnetically Controlled Sorbents," Turkish Journal of Computer and Mathematics Education (TURCOMAT), vol. 12, no. 5, pp. 515-519, 2021.

[9] N. A. Bulychev, L. N. Rabinskiy, O. V. Tushavina, "Effect of intense mechanical vibration of ultrasonic frequency on thermal unstable low-temperature plasma,"
Nanoscience and Technology: An International Journal, 11 (1), pp. 15-21, 2020.

[10] O. A. Butusova, "Application of Magnetically Controlled Sorbents for Detoxication," Turkish Journal of Computer and Mathematics Education (TURCOMAT), vol. 12, no. 5, pp. 520-524, 2021.

[11]O. V. Tushavina, "Coupled heat transfer between a viscous shock gasdynamic layer and a transversely streamlined anisotropic half-space," INCAS Bulletin, 12 (Special Issue), pp. 211-220, 2020.

[12]N. A. Kucheva, V. Kohlert, "Mathematical modeling methods for estimation the thermophysical properties of heat-protective composite materials," Turkish Journal of Computer and Mathematics Education (TURCOMAT), vol. 12, no. 10, pp. 1606-1612, 2021.

[13] S. Vakhneev, E. Starovoitov, "Damping of circular composite viscoelastic plate vibration under neutron irradiation," Journal of Applied Engineering Science, 18(4), pp. 699-704, 2020.

[14] V. A. Pogodin, L. N. Rabinskii, S. A. Sitnikov, "3D Printing of Components for the Gas-Discharge Chamber of Electric Rocket Engines," Russian Engineering Research, vol. 39, no. 9, pp. 797-799, 2019.

[15] O. A. Pashkov, "Influence of Polymer Coatings on the Mechanical Properties of Steel Samples in Tensile and Bending Tests," Turkish Journal of Computer and Mathematics Education (TURCOMAT), vol. 12, no. 5, pp. 542-548, 2021.

[16] O. A. Pashkov, "Investigation of the Effect of Steel Plate Size and Elevated Temperature on Critical Load in Stability Tests," Turkish Journal of Computer and Mathematics Education (TURCOMAT), vol. 12, no. 10, pp. 1657-1663, 2021.

[17] Y. Sun, O. V. Egorova, E. L. Kuznetsova, "Identification of the front angle of a plane acoustic oblique pressure wave on convex surfaces with the use of analytical solution," Journal of the Balkan Tribological Association, 27(2), pp. 189-197, 2021.

[18] O. A. Pashkov, "Theoretical calculation of the thickness of interphase zones in the Al-Al2O3 composite," Turkish Journal of Computer and Mathematics Education (TURCOMAT), vol. 12, no. 10, pp. 1672-1677, 2021.

[19] O. A. Pashkov, "Experimental and Theoretical Study of Mechanical Properties of Matrix Composite Materials," Turkish Journal of Computer and Mathematics Education (TURCOMAT), vol. 12, no. 10, pp. 1678-1684, 2021.

[20] Y. K. Kyaw, E. L. Kuznetsova, A. V. Makarenko, "Complex mathematical modelling of mechatronic modules of promising mobile objects," INCAS Bulletin, 12(Special Issue), pp. 91-98, 2020.

[21] L. E. Kuznetsova, V. G. Fedotenkov, "Dynamics of a spherical enclosure in a liquid during ultrasonic cavitation," Journal of Applied Engineering Science, 18(4), pp. $681-686,2020$.

[22]A. V. Makarenko, E. L. Kuznetsova, "Energy-Efficient Actuator for the Control System of Promising Vehicles," Russian Engineering Research, 39(9), pp. 776-779, 2019. 
[23] O. A. Butusova, "Surface Modification of Titanium Dioxide Microparticles Under Ultrasonic Treatment," International Journal of Pharmaceutical Research, vol. 12, i. 4, pp. 2292-2296, 2020.

[24] O. A. Butusova, "Stabilization of Carbon Microparticles by High-Molecular Surfactants," International Journal of Pharmaceutical Research, vol. 12, Supplementary Issue 2, pp. 1147-1151, 2020.

[25] Yu. V. Ioni, A. Ethiraj, "New Tailor-Made Polymer Stabilizers for Aqueous Dispersions of Hydrophobic Carbon Nanoparticles," International Journal of Pharmaceutical Research, vol. 12, i. 4, pp. 3443-3446, 2020.

[26] Yu. V. Ioni, "Nanoparticles of noble metals on the surface of graphene flakes," Periodico Tche Quimica, vol. 17, no. 36, pp. 1199-1211, 2020.

[27] O. A. Butusova, "Vinyl Ether Copolymers as Stabilizers of Carbon Black Suspensions," International Journal of Pharmaceutical Research, vol. 12, Supplementary Issue 2, pp. 1152-1155, 2020.

[28] M. O. Kaptakov, "Catalytic Desulfuration of Oil Products under Ultrasonic Treatment," International Journal of Pharmaceutical Research, vol. 12, Supplementary Issue 2, pp. 1838-1843, 2020.

[29]B. A. Garibyan, "Enhancement of Mechanical Properties of Inorganic Glass under Ultrasonic Treatment," International Journal of Pharmaceutical Research, vol. 12, Supplementary Issue 2, pp. 1829-1832, 2020.

[30]M. O. Kaptakov, "Enhancement of Quality of Oil Products under Ultrasonic Treatment," International Journal of Pharmaceutical Research, vol. 12, Supplementary Issue 2, pp. 1851-1855, 2020.

[31]O. A. Butusova, "Adsorption Behaviour of Ethylhydroxyethyl Cellulose on the Surface of Microparticles of Titanium and Ferrous Oxides," International Journal of Pharmaceutical Research, vol. 12, Supplementary Issue 2, pp. 1156-1159, 2020.

[32]A. N. Tarasova, "Vibration-based Method for Mechanochemical Coating Metallic Surfaces," International Journal of Pharmaceutical Research, vol. 12, Supplementary Issue 2, pp. 1160-1168, 2020.

[33]B. A. Garibyan, "Mechanical Properties of Electroconductive Ceramics," International Journal of Pharmaceutical Research, vol. 12, Supplementary Issue 2, pp. 1825-1828, 2020.

[34]M. O. Kaptakov, "Effect of Ultrasonic Treatment on Stability of $\mathrm{TiO}_{2}$ Aqueous Dispersions in Presence of Water-Soluble Polymers," International Journal of Pharmaceutical Research, vol. 12, Supplementary Issue 2, pp. 1821-1824, 2020.

[35] Yu. V. Ioni, "Synthesis of Metal Oxide Nanoparticles and Formation of Nanostructured Layers on Surfaces under Ultrasonic Vibrations," International Journal of Pharmaceutical Research, vol. 12, i. 4, pp. 3432-3435, 2020.

[36]A. N. Tarasova, "Effect of Reagent Concentrations on Equilibria in Water-Soluble Complexes," International
Journal of Pharmaceutical Research, vol. 12, Supplementary Issue 2, pp. 1169-1172, 2020.

[37] G. A. Kalugina, A. V. Ryapukhin, "Impact of the 2020 Pandemic on Russian Aviation," Russian Engineering Research, vol. 41. no. 7, pp. 627-630, 2021.

[38]R. N. Zaripov, I. M. Murakaev, A. V. Ryapukhin, "Development of the Organization's Key Performance Indicators System in Order to Improve the Effectiveness of Its Human Capital and Risk Management," TEM Journal, vol. 10, no. 1, pp. 298-302, 2021.

[39] A. A. Kalugin, G. A. Kalugina, A. V. Ryapukhin, "Informational Support for the Sale of Passenger Aircraft," Russian Engineering Research, vol. 41, no. 2, pp. 183-187, 2021.

[40]R. N. Zaripov, I. M. Murakaev, S. V. Novikov, A. V. Ryapukhin, "Corporate Structure for Innovative Enterprises," Russian Engineering Research, vol. 40, no. 2, pp. 137-139, 2020.

[41]A. Y. Burova, "Concept of multistage discrete fourier transform without performing multiplications" Journal of Physics: Conference Series, vol. 1889, no. 2, 022003, 2021.

[42] A. Burova, "Reducing the Error of Digital Algorithms for Deductive Signal Processing Based on Their Multi-Stage Discrete Fourier Transform by the Difference Digital Filters," 22th International Conference on Digital Signal Processing and its Applications, DSPA 2020, no. 9213275, 2020.

[43] A. Y. Burova, "Minimization of asymmetry of thrust of dual-flow turbojet engines of airliner in accordance with the results of system analysis of thrust parameters," Asia Life Sciences, no. 2, pp. 629-643, 2019.

[44]A. N. Tarasova, "Effect of Vibration on Physical Properties of Polymeric Latexes," International Journal of Pharmaceutical Research, vol. 12, Supplementary Issue 2, pp. 1173-1180, 2020.

[45] Yu. V. Ioni, A. Ethiraj, "Study of Microparticles Surface Modification by Electrokinetic Potential Measuring," International Journal of Pharmaceutical Research, vol. 12, i. 4, pp. 3436-3439, 2020.

[46] Yu. V. Ioni, "Effect of Ultrasonic Treatment on Properties of Aqueous Dispersions of Inorganic and Organic Particles in Presence of Water-Soluble Polymers," International Journal of Pharmaceutical Research, vol. 12, i. 4, pp. 3440-3442, 2020.

[47] M. O. Kaptakov, "Effect of Thin Polymer Layers on Mechanical Properties of Metal Surfaces," Turkish Journal of Computer and Mathematics Education (TURCOMAT), vol. 12, no. 5, pp. 525-529, 2021.

[48] B. A. Garibyan, "Determination of the Elastic Modulus of the Coating Using a Spherical Indenter," Turkish Journal of Computer and Mathematics Education (TURCOMAT), vol. 12, no. 10, pp. 1594-1600, 2021.

[49]N. A. Bulychev, A. V. Ivanov, "Effect of vibration on structure and properties of polymeric membranes," International Journal of Nanotechnology, vol. 16, nos. 6/7/8/9/10, pp. $334-343,2019$. 
[50] N. A. Bulychev, A. V. Ivanov, "Nanostructure of OrganicInorganic Composite Materials Based on Polymer Hydrogels," International Journal of Nanotechnology, vol. 16, nos. 6/7/8/9/10, pp. $344-355,2019$.

[51] N. A. Bulychev, A. V. Ivanov, "Study of Nanostructure of Polymer Adsorption Layers on the Particles Surface of Titanium Dioxide," International Journal of Nanotechnology, vol. 16, nos. 6/7/8/9/10, pp. $356-365$, 2019.

[52] M. O. Kaptakov, "Modelling of Mechanical Properties of Metal Plates with Polymer Coatings," Turkish Journal of Computer and Mathematics Education (TURCOMAT), vol. 12, no. 5, pp. 530-534, 2021.

[53] B. A. Garibyan, "Theoretical Estimations of Influence of Polymer Coatings on the Elastic Modulus and Ultimate Strength of Steel Samples," Turkish Journal of Computer and Mathematics Education (TURCOMAT), vol. 12, no. 10, pp. 1651-1656, 2021.

[54] M. O. Kaptakov, "Investigation of Effective Mechanical Characteristics of Nanomodified Carbon-Epoxide Composite by Numerical and Analytical Methods," Turkish Journal of Computer and Mathematics Education (TURCOMAT), vol. 12, no. 5, pp. 535-541, 2021.

[55]M. O. Kaptakov, "Obtaining of Carbon Fibers Based Composite Materials and Study of Their Mechanical Properties," Turkish Journal of Computer and Mathematics Education (TURCOMAT), vol. 12, no. 10, pp. 1601-1605, 2021.

[56] N. A. Kucheva, "Investigation of the mechanical properties of heat-protective highly porous composite materials using the effective medium model," Turkish Journal of Computer and Mathematics Education (TURCOMAT), vol. 12, no. 10, pp. 1613-1621, 2021.

[57]N. A. Bulychev, E. L. Kuznetsova, "Ultrasonic Application of Nanostructured Coatings on Metals," Russian Engineering Research, 39 (9), pp. 809-812, 2019.

[58] N. A. Bulychev, V. V. Bodryshev, L. N. Rabinskiy, "Analysis of geometric characteristics of two-phase polymer-solvent systems during the separation of solutions according to the intensity of the image of micrographs," Periodico Tche Quimica, 16(32), pp. 551559, 2019.

[59] S. A. Kolesnik, N. A. Bulychev, "Numerical analytic method for solving the inverse coefficient problem of heat conduction in anisotropic half-space," Journal of Physics: Conference Series, 1474(1), 012024, 2020.

[60] V. F. Formalev, N. A. Bulychev, S. A. Kolesnik, M. A. Kazaryan, "Thermal state of the package of cooled gasdynamic microlasers," Proceedings of SPIE - The International Society for Optical Engineering, 11322, article number $113221 \mathrm{~B}, 2019$

[61] N. A. Kucheva, V. Kohlert, "Analytical solution of the problem of thermoelasticity for a plate heated by a source with a constant heat supply on one surface," Turkish Journal of Computer and Mathematics Education (TURCOMAT), vol. 12, no. 10, pp. 1622-1633, 2021.

[62]E. L. Kuznetsova, A. V. Makarenko, "Mathematic simulation of energy-efficient power supply sources for mechatronic modules of promising mobile objects," Periodico Tche Quimica, 15(Special Issue 1), pp. 330338, 2018.

[63] Y. Li, A. M. Arutiunian, E. L. Kuznetsova, G. V. Fedotenkov, "Method for solving plane unsteady contact problems for rigid stamp and elastic half-space with a cavity of arbitrary geometry and location," INCAS Bulletin, 12(Special Issue), pp. 99-113, 2020.

[64] E. L. Kuznetsova, G. V. Fedotenkov, E. I. Starovoitov, "Methods of diagnostic of pipe mechanical damage using functional analysis, neural networks and method of finite elements," INCAS Bulletin, 12(Special Issue), pp. 79-90, 2020.

[65]Y. K. Kyaw, P. F. Pronina, P. O. Polyakov, "Mathematical modelling of the effect of heat fluxes from external sources on the surface of spacecraft," Journal of Applied Engineering Science, 18(4), pp. 732-736, 2020.

[66] A. N. Astapov, E. L. Kuznetsova, L. N. Rabinskiy, "Operating capacity of anti-oxidizing coating in hypersonic flows of air plasma," Surface Review and Letters, 26(2), pp. 1850145, 2019.

[67] L. N. Rabinskiy, O. V. Tushavina, E. I. Starovoitov, "Study of thermal effects of electromagnetic radiation on the environment from space rocket activity," INCAS Bulletin, 12 (Special Issue), pp. 141-148, 2020.

[68]N. A. Bulychev, L. N. Rabinskiy, "Ceramic Nanostructures Obtained by Acoustoplasma Technique," Nanoscience and Technology: An International Journal, 10 (3), pp. 279-286, 2019.

[69] A. V. Babaytsev, A. A. Orekhov, L. N. Rabinskiy, "Properties and microstructure of AlSi10Mg samples obtained by selective laser melting," Nanoscience and Technology: An International Journal, 11(3), pp. 213222, 2020.

[70] O. V. Egorova, Y. K. Kyaw, "Solution of inverse nonstationary boundary value problems of diffraction of plane pressure wave on convex surfaces based on analytical solution," Journal of Applied Engineering Science, 18(4), pp. 676-680, 2020.

[71] I.P. Lifanov, A. N. Astapov, V. S. Terentieva, "Deposition of heat-resistant coatings based on the $\mathrm{ZrSi} 2-\mathrm{MoSi} 2-\mathrm{ZrB} 2$ system for protection of non-metallic composite materials in high-speed high-enthalpy gas flows," Journal of Physics: Conference Series, vol. 1713, no. 1, pp. 012025 , 2020.

[72] I. P. Lifanov, A. A. Yurishcheva, A. N. Astapov, "Hightemperature protective coatings on carbon composites," Russian Engineering Research, vol. 39, no. 9, pp. 804 808, 2019.

[73] A. N. Astapov, I. P. Lifanov, M. V. Prokofiev, "Hightemperature interaction in the $\mathrm{ZrSi} 2-\mathrm{ZrSiO} 4$ system and its mechanism," Russian Metallurgy (Metally), no. 6, pp. $640-646,2019$. 
INTERNATIONAL JOURNAL OF CIRCUITS, SYSTEMS AND SIGNAL PROCESSING

\section{Creative Commons Attribution License 4.0}

(Attribution 4.0 International, CC BY 4.0)

This article is published under the terms of the Creative Commons Attribution License 4.0

https://creativecommons.org/licenses/by/4.0/deed.en_US 